\title{
Chapter 82 \\ Cultural Perspectives on Advertising Perceptions and Brand Trustworthiness
}

\author{
Annie Danbury \\ University of Bedfordshire, $U K$ \\ Maria Palazzo \\ University of Salerno, Italy \\ Kathleen Mortimer \\ University of Northampton, $U K$ \\ Alfonso Siano \\ University of Salerno, Italy
}

\begin{abstract}
The creation of a trustworthy brand identity through advertising has received relatively little attention in European marketing research. Thus, in this chapter, we explore this relationship by undertaking focus group research in the UK and Italy to identify the characteristics of print advertisements perceived as portraying a trustworthy image. The results show that advertisements that are simple, straightforward and clear are perceived as being more trustworthy. However, findings in this chapter also show some differences between our national samples in relation to factors such as colour perception and consumer ethnocentrism. Young consumers are also quite critical of current advertising efforts in building a trustworthy brand image. A discussion of potential solutions and future research directions is provided.
\end{abstract}

\section{INTRODUCTION ${ }^{1}$}

In the current turbulent environment, each global company is interested in examining the factors that affect the perception and evaluation of corporate brands. Among these, the appropriateness of the attitude towards brands emerges as a point of parity and intrinsic interest. Starting from a literature review on brand trustworthiness, and related elements, the moderating role of these issues is studied within different 
contexts in a preliminary empirical research. The purpose of this study is to explore how young adults (18-23 years and in university education), and also a sub-segment of Generation Y, evaluate advertising and brands in relation to trustworthiness. Specifically, we explore perceptions of trustworthiness from two groups of consumers in the UK and Italy. Generation Y are widely recognised as an important consumer group worldwide in terms of their aggregate spending (Cui, Trent, Sullivan, \& Matiru, 2003) and is also known for their sceptical attitude towards advertising and media (Hyllegard, Yan, Ogle, \& Attmann, 2011). Hence this group of consumers is particularly interesting to research in order to identify which aspects of advertisements assist in portraying a trustworthy brand image or not. We also explore the reasons for trusting specific brands and compare advertising perceptions between two cultures that share some cultural dimensions whilst they also differ on others based on dimensions of the GLOBE project (Javidan \& House, 2001). The chapter is structured as follows: firstly, a conceptual view of brand trustworthiness is provided followed by a description of the research study including methodology, analysis and discussion of the findings, main contributions of the study, and, finally, conclusions.

\section{BACKGROUND}

The importance of corporate image associations in brand evaluations is well-established in the literature (Gürham-Canli \& Batra, 2004). A number of such corporate image associations have been identified over the years as innovativeness, dynamism, imaginativeness, quality of goods and services, perceived honesty and trustworthiness, social responsibility, investment value, quality of management, helpfulness and friendliness, and conservative versus informal corporate culture (see e.g. Dowling, 1986; Ambler, 1997). Research has shown that consumers are likely to pay particular attention to associations of innovation, trustworthiness and corporate social responsibility (CSR). An experiment by Gürham-Canli and Batra (2004) demonstrated that consumers are more likely to use such diagnostic information as innovativeness and trustworthiness than other types of associations when there is a higher risk of product failure. In this chapter we concentrate on the importance of brand trustworthiness in the evaluation of advertising information about experience products and service brands as these are considered to be of higher perceived risk compared to consumables. Higher perceived risk generally leads to risk reducing strategies such as more evaluation of product alternatives in purchase situations, trial, and deeper processing of product information in advertisements and other promotional material (Bennett, Härtel, \& McColl-Kennedy, 2005). Essentially, trustworthiness relates to an overall assessment of brand (image) credibility and a trustworthy brand reputation can have a positive impact on brand equity (Chen \& Dhillon, 2003; Gounaris \& Vlasis, 2004). For example, Chaudhuri and Holbrook (2001) examined 107 brands and found that brand trustworthiness had a strong impact on brand loyalty in both its forms i.e. attitudinal loyalty and purchase loyalty which then led to increases in market share and premium pricing. Delgado-Ballester and Munuera-Aleman $(2004,2005)$ also found a positive relationship between brand trust, brand loyalty and brand equity. Hence, brand trustworthiness leads to many positive outcomes for the brand owner. It is therefore important to establish how it can be created. 


\section{MAIN FOCUS OF THE CHAPTER}

\section{Creating a Trustworthy Brand Image}

In accordance with the definition of trust provided by Morgan and Hunt (1994, p. 23), we delineated trust as the motivation of the consumer to rely on the capability of the brand to complete its settled function. Some brands adopt an explicit approach to creating a trustworthy brand image by using specific wording, e.g. 'trust' in their advertising copy. An example of this is a current radio advertisement for Country Vehicles, a car repair company in the UK, using the slogan: "A service you can trust". Such message framing may indeed be necessary to focus information processing when advertising high involvement services that are usually considered higher risk than products (Lantieri \& Chiagouris, 2009). In fact, Moorman, Zaltman, \& Deshpande, (1992) and Doney and Cannon (1997) also emphasize that the concept of trust is mainly relevant in situations of uncertainty, when differences among brands arise. In particular, trust decreases the uncertainty because they know they can rely on the trusted brand. Indeed, an experiment by Li and Miniard (2006) found that the inclusion of the words "You can trust us to do the job for you" had an impact on the number of positive thoughts about the advertisement and the fictitious car repair company advertised. The brand was perceived to be more trustworthy compared to the advertisement without those words and consequently purchase intention increased. "To be an effective competitor (in the global economy) requires one to be a trusted co-operator (in some network)" (Morgan \& Hunt, 1994, p. 21). This network nowadays, does not include only companies but also prosumers (Toffler, 1980): this means that customers do not just trust company's performances but they also try to be involved in the whole process of creating products/services and/or communication campaigns.

A more implicit approach to creating a trustworthy brand image in advertising is the use of endorsers. Studies show that the credibility of an endorser, which should contain the three dimensions of expertise, trustworthiness and attractiveness, can have a direct impact on attitude to the advertisement and the perceived credibility of the brand through association (Lafferty, Goldsmith, \& Newell, 2002; Spry, Pappu, \& Cornwell, 2011). A study by Garretson and Niedrich (2004) specifically examined the role of fictitious spokes-characters in advertising, such as Michelin Man, and how they are perceived by consumers as trustworthy. Their results show that trustworthiness is linked to the perceived expertise of the character and the level of nostalgia that it brings and this has a positive effect on brand attitude. Therefore, the use of celebrities could also bring in a positive image among the consumers for the brand. Moreover, the "cue utilization theory" (Richardson, Dick, \& Jain, 1994, p. 29) proposes that endorsements can be used as an extrinsic cue pressuring consumers' opinions of product quality. Product quality, according to Reast (2005, p. 5), is a cognitive component of brand trustworthiness. Thus, the link between endorsement and brand trustworthiness is indirectly implied, due to the fact that product quality is one of the factors that make up brand trustworthiness as part of a complex construct.

According to Keller (1993) brand knowledge is positively related to brand trust and increased brand awareness and exposure to more favourable brand images result in greater trust in the brand. Such brand knowledge is created via three major information sources for consumers and these are believed to be user experience, word-of-mouth (WOM) and advertising (Xingyuan, Li, \& Wei, 2010). Thus all three sources of information contribute to brand knowledge in different ways which in turn affects brand trustworthiness (Johnson \& Grayson, 2005). Whilst user experience is widely acknowledged as performing a 
predominant role in consumer trust formation, the work by Xingyuan et al. (2010) demonstrated a more nuanced construct of trust formation in that advertising was good at increasing brand awareness, product knowledge and company knowledge whereas WOM was more effective at changing consumers' value perception. Indeed, advertising has been found to increase the perceived trustworthiness of even unknown brands when the advertising message was framed to include a simple trust appeal (Li \& Miniard, 2006). This points to advertising as an important source of information to communicate a trustworthy brand image for brand owners who wish to compete in an increasingly competitive global market.

\section{Impact of Culture on Brand Trustworthiness}

Cultural knowledge is important to managers in order to inform appropriate and culturally sensitive decisions and a number of cultural differences would be expected in consumers' perception of advertising and perceptions of trustworthy brands. The dimensions of the GLOBE Project (Javidan \& House, 2001) are one way of distinguishing one culture from another. Nine dimensions were developed from the GLOBE (Global Leadership and Organizational Behaviour Effectiveness) research project which involved 150 researchers collecting data over seven years from 18,000 managers in 62 countries. These dimensions have important managerial implications and are based on a set of shared beliefs that distinguish one society from another and comprise the following: Performance orientation, future orientation, assertiveness, uncertainty avoidance, power distance, collectivism, family collectivism, gender differentiation and humane orientation. Country-specific findings from the GLOBE project indicated that Italy and the UK belong to the medium cluster of the Power-Distance dimension which is defined by the "establishment and maintenance of dominance and control of the less powerful by the more powerful" (Javidan \& House, 2001, p. 296). That is to say, both UK and Italian individuals would expect a reasonably balanced (e.g. trusting) relationship with authority as represented here by advertising and brand messages. On the other hand, Italy and the UK belong to different clusters of the Performance Orientation dimension which refers to "the degree to which a society encourages and rewards group members for performance improvement and excellence" (Javidan \& House, 2001, p. 300). Actually, Italy belongs to the least performance oriented countries and so value loyalty and belongingness more compared to the UK in the medium level cluster. Taking into consideration the GLOBE project, the two countries seem to share similarities but also some differences in cultural terms.

When trading with other cultures key management decisions have to be made whether or not to use standardized branding. Many scholars and researchers argue that standardised branding is neither reasonable nor suitable (Clark, 1987) due to cultural dissimilarities (Bradley, 1991; Mead, 1993). For example, Schmitt and Pan (1994) highlighted that cultural features typical of Asia-Pacific customers were seen to affect brand choice. In this case, brand names were preferred or not, "depending on the balance of Yin and Yang and the number of strokes in the letters" (Grimes \& Doole, 1998, p. 802). Other authors advocate the idea of creating international brands with standard components. This strategy can help companies to take advantage of economies of scale (Littler \& Schlieper, 1995). Besides, while it is generally believed that the foundation of strong associations is the basis for brand image and trustworthiness, it should also be taken into account that the cohesiveness of the brand image could affect the efficacy of these associations. Unless a constant and well-organized brand image is built, only some of the potentially retrievable associations may be recalled (Keller, 1993). 
Cultural Perspectives on Advertising Perceptions and Brand Trustworthiness

\section{Issues of Consumer Etnocentrism}

An interesting observation was made by a former CEO of Coca-Cola, Doug Ivestor, that 'as economic barriers come down, cultural barriers go up, presenting new challenges and opportunities in business' (cited in Javidan \& House, 2001, p. 291). Thus trustworthiness can also be linked to concepts such as consumer ethnocentrism and consumer nationalism. Consumer ethnocentrism forms part of the wider subject of ethnocentrism introduced more than 80 years ago by Sumner (1906), a sociological topic used to distinguish "closed groups" (those groups with which individuals identify themselves) and "open groups" (those considered to be antithetical to "closed groups"). In the last decades, ethnocentrism has become an established psycho-sociological subject applicable to a rich variety of fields of study. Shimp and Sharma (1987) define consumer ethnocentrism (CET) as the belief held by consumers about the appropriateness and morality of purchasing foreign-made products. In essence, the concept of ethnocentrism refers to the practice of assessing the group which the individual contact forming the centre of the purchasing universe. Alternatively, other groups/people are considered and compared taking into consideration the perspective of "the" group, for this reason people who are culturally dissimilar could be rejected or considered improper (Sharma, Shimp, \& Shin, 1995). The symbols and values of "the" ethnic or national group create a sense of pride and attachment, whereas symbols of other groups may be disapproved (Thakor \& Kohli, 1996). Thus, consumer ethnocentrism represents the consumers' feelings of appropriateness and morality, a consideration set they refer to as they purchase products manufactured abroad. Lantz and Loeb (1996) proposed that ethnocentric consumers prefer products created by culturally similar countries; however, they suggested that this is true only if a national alternative is not available.

In other studies, consumer ethnocentrism represents a further consideration as an additional 'component' of consumer nationalism. Following Keillor and Hult (1999), national identity is a complex entity, consisting of four significant component parts (ethnocentrism, belief structure, cultural homogeneity and national heritage) which influence consumer beliefs, and most importantly, the interpretations about the consumption experience. In brief, consumer nationalism may be considered an expression of one's national identity that makes individuals identifying it in products and/or brands that reflect national identity. According to Wang (2005), consumer nationalism has a significant impact on corporate reputation too.

In the discussion on collective (national) and individual identity, a further complication arises when we consider that (strong) brands may become cultural symbols that are also related to a consumer's self-identity (Kay, 2006). In this sense, brands and brand trustworthiness become expressions/signs of particular mindset and become central in consumption choice. Nevertheless, among the drivers of consumer attitudes toward local/global brands some recent studies (Ashill \& Sinha, 2004) show that the components of brand equity through the effect of brand loyalty and trustworthiness are three times more important than consumer ethnocentrism effects. Indeed, brand loyalty cannot be considered as conflicting with consumer nationalism, but may mitigate the role of ethnocentric/nationalistic attitude (Pappu, Quester, \& Cooksey, 2006).

In addition, other aspects that are worthy to be evaluated are consumers' attitudes toward the brand and their usage history (i.e. replication of brand selection in consumer's family) as it may be an important driver of preference towards local products/brands without involving nationalistic/identitary considerations (East, 1996; Macdonald \& Sharp, 2000).

Whilst most studies on advertising and brand trustworthiness have been undertaken in the USA, our study follows on from the work of Li and Miniard (2006) by examining advertising for high involvement services in a European context of two cultures and is designed to answer the following research questions: 
Cultural Perspectives on Advertising Perceptions and Brand Trustworthiness

- What ingredients do advertisements portraying a trustworthy brand image have that others don't?

- What makes people trust specific brands?

- Do UK and Italian advertising perceptions differ in relation to brand trustworthiness?

\section{Design, Approach and Methodology}

In order to explore the subject further, focus group research was undertaken in the UK and Italy during 2012. Three focus groups were conducted in the UK with Marketing 1st and 2nd year undergraduate students, containing a total of 38 student perceptions. A corresponding number of perceptions were generated from 39 Italian students between the ages of 19-23. Young people such as university students are an important segment for the three service categories included in this study, namely mobile telephone services, financial services and travel operators. The sample was selected in order to ensure that all participants were similar in terms of age, occupation, and level of education; therefore the research tried to separate the cultural facet as the main diversity between participants from the two countries. Considering the exploratory nature of our research, the selection of respondents was not made according to probabilistic criteria, hence our sample is made up of a complete set of 77 valid questionnaires, equally distributed in the two countries.

Participants were shown nine advertisements which appeared in the Metro free London newspaper on Wednesday 15th February 2012. The questionnaires were distributed face-to-face, between February and October 2012. It was not felt necessary for the participants to be familiar with all the brands as it was their response to the advertisements for the three groups of high involvement services which was initially of interest to us. Similarly, the advertisements were kept in English as the stimulus material was considered straight forward and unlikely to cause any language difficulties.

Each advertisement was presented to participants on slides and they were given one minute to write down whether they found the information contained in the advertisements trustworthy and 'why/why not'. They were then shown the three advertisements together and asked to compare them in terms of portraying a trustworthy brand image. Lastly they were required to step back and describe the brands they trusted within that category more generally. This process was repeated for all three product categories. When all advertisements had been examined the participants were asked to indicate a brand that they found most trustworthy and why. Finally, participants were asked how they felt about advertisements generally in terms of trustworthiness. Once the form had been completed there was a general discussion with the group about brand trustworthiness to pick up any issues that the questionnaire may not have captured.

\section{Findings and Discussion}

Tables 1-6 present the responses that were received from asking the question: "Do you trust this ad: why/why not?" Selections of both positive and negative comments have been included for each advertisement to represent the main issues that were raised. The underlined brand in each table indicates the advertisement that was perceived to be most trustworthy out of the three. Interestingly, this decision was unanimous across all focus groups in the UK and Italy for the most trustworthy financial services brand, Lloyds. However, differences between the two samples for the other service categories will be discussed further in the following section.

The examination of comments in the three categories revealed some interesting findings. Firstly, it would seem that an advertisement needs to be very simple and straightforward in its communications in 
Table 1. Advertisements for mobile telephone service providers (UK)

\begin{tabular}{|l|l|l|}
\hline \multicolumn{1}{|c|}{ Mobile Tel. } & \multicolumn{1}{c|}{ YES } & \multicolumn{1}{c|}{ NO } \\
\hline \multirow{2}{*}{ Tesco } & Clear facts and figures including price. & I don't associate Tesco with mobiles \\
\cline { 2 - 3 } & Award, simple design, realistic & There is always a catch! \\
\hline \multirow{3}{*}{ Virgin } & Clear terms and conditions & Lots of small print \\
\cline { 2 - 3 } & Break down of service features & Nothing is free! \\
\hline \multirow{3}{*}{3} & Nicely laid out & Downloads hard to measure \\
\cline { 2 - 3 } & Simple & Not much information \\
\hline Trusted brands in this category & Orange, O2, Tesco, T-Mobile, Virgin, Vodaphone \\
\hline
\end{tabular}

Table 2. Advertisements for mobile telephone service providers (Italy)

\begin{tabular}{|l|l|l|}
\hline \multicolumn{1}{|c|}{ Mobile Tel. } & \multicolumn{1}{|c|}{ YES } & \multicolumn{1}{c|}{ NO } \\
\hline \multirow{2}{*}{ Tesco } & Good price. & Layout not professional, prices seem too low \\
\cline { 2 - 3 } & Realistic, simple, essential & Not clear, don't know the brand \\
\hline \multirow{3}{*}{ Virgin } & Lots of details & Don't know the brand, confused \\
\cline { 2 - 3 } & Realistic, not confusing & I don't associate Virgin with mobile phones \\
\hline \multirow{3}{*}{$\underline{*}$} & Well known brand & Too simple, images not real \\
\cline { 2 - 3 } & Clear, good price & $\begin{array}{l}\text { Too much focus on aesthetic elements. They } \\
\text { want to hide something, don't trust the brand }\end{array}$ \\
\hline Trusted brands in this category & Tim, Vodafone, 3, Wind \\
\hline
\end{tabular}

Table 3. Advertisements for financial service providers (UK)

\begin{tabular}{|l|l|l|}
\hline \multicolumn{1}{|c|}{ Financial services } & \multicolumn{1}{c|}{ YES } & \multicolumn{1}{c|}{ NO } \\
\hline \multirow{2}{*}{ Halifax } & Happy customers & Looks cheesy \\
\cline { 2 - 3 } & Clear statements and offers & Small print - hidden costs \\
\hline \multirow{2}{*}{ HSBC } & They look serious about money & Don't like the word “free" \\
\cline { 2 - 3 } & Look professional & No images, too many words \\
\hline \multirow{2}{*}{ Lloyds } & Straight to the point & Juvenile \\
\cline { 2 - 3 } & Simple and fresh & Don't trust banks \\
\hline Trusted brands in this category & Santander, Natwest, Lloyds, HSBC, Nationwide, Barclays, Halifax, Nationwide; \\
\hline
\end{tabular}

order to be perceived as honest and trustworthy. When advertisements suggest that something is 'free' or a good deal people become suspicious and are looking for the catch. All information needs to be presented clearly and be straight to the point. This seems to be in line with what we summarised in the literature review: information contribute to brand knowledge in different ways which in turn can affect brand trustworthiness (Johnson \& Grayson, 2005).

The amount of information that the advertisement should contain is difficult to define as advertisements were criticised for having too little as well as too much information. Certainly a large amount of 
Cultural Perspectives on Advertising Perceptions and Brand Trustworthiness

Table 4. Advertisements for financial service providers (Italy)

\begin{tabular}{|l|l|l|}
\hline \multicolumn{1}{|c|}{ Financial services } & \multicolumn{1}{c|}{ YES } & \multicolumn{1}{c|}{ NO } \\
\hline \multirow{2}{*}{ Halifax } & Lots of details & Don't like contrast between images and text \\
\cline { 2 - 3 } & Like that shows people, faces & Too dark, too many stereotypes \\
\hline \multirow{2}{*}{ HSBC } & It uses a direct communication. & No colours, Only text \\
\cline { 2 - 3 } & Doesn't distract our attention with figures & No visual impact, boring \\
\hline \multirow{2}{*}{ Lloyds } & Like picture, simple & Too simple, need more info \\
\cline { 2 - 3 } & Very few small prints & Too unbalanced, too ingenuous \\
\hline Trusted brands in this category & Intesa-san paolo, UniCredit (12 respondents don't remember any brand in this category) \\
\hline
\end{tabular}

Table 5. Advertisements for travel service providers (UK)

\begin{tabular}{|l|l|l|}
\hline \multicolumn{1}{|c|}{ Holidays } & \multicolumn{1}{c|}{ YES } & \multicolumn{1}{c|}{ NO } \\
\hline \multirow{2}{*}{ Globalenduro } & People having fun & Not enough information \\
\cline { 2 - 3 } & Contact details and links to social networks & No reference to price \\
\hline \multirow{2}{*}{ Virgin } & Simple and clear & Prices "from" suggests extra costs \\
\cline { 2 - 3 } & Good to have prices & "sale ends tonight!" cheapens the brand \\
\hline \multirow{2}{*}{ Kesari } & Straightforward pricing & Advert looks cheap \\
\cline { 2 - 3 } & More specific details & Too much text and stuff going on. \\
\hline Trusted brands in this category & Virgin, BA, Thomas Cook, First Choice, Last.minute.com, Thomson, expedia \\
\hline
\end{tabular}

Table 6. Advertisements for travel service providers (Italy)

\begin{tabular}{|l|l|l|}
\hline \multicolumn{1}{|c|}{ Holidays } & \multicolumn{1}{c|}{ YES } & \multicolumn{1}{c|}{ NO } \\
\hline \multirow{2}{*}{ Globalenduro } & Shows facebook & Not clear, too adventurous \\
\cline { 2 - 3 } & Lots of pictures, colours, countries & Doesn't look like an advert \\
\hline \multirow{2}{*}{ Virgin } & Good price. & It doesn't seem focused on holidays \\
\cline { 2 - 3 } & Good balance text/images, strong brand & Monochromatic, small print \\
\hline \multirow{2}{*}{ Kesari } & Focus on places & Too many prices, difficult to focus \\
\cline { 2 - 3 } & Prices seem real, good image & Small print, not catching image \\
\hline Trusted brands in this category & Valtour, Easyjet, Expedia & \\
\hline
\end{tabular}

small print is perceived negatively and needs to be handled with care. A study by Wang (2010) highlights the impact of responsible communication in relation to disclosure information (terms and conditions of sale) in print advertisements. The experiment found that visual priming of disclosure information in mobile telephone advertisements helped to increase the level of trustworthiness towards the print advertisement, and this in turn had a positive impact on the attitudes toward the mobile telephone company. A comparison of the nine advertisements in our explorative study highlights a larger amount of disclosure information in the mobile telephone advertisements compared to both financial services and travel company advertisements. Disclosure information within the mobile telephone advertisements in our study 
might also be considered not to be visually primed given the small size of the text and the position at the bottom of the advertisement and hence not following good practice for responsible communication. Whilst our sample generally found advertisements useful in providing knowledge of products/brands and promoting offers, they would not fully trust the advertisements. A coping strategy in such situations includes additional research (e.g. on websites) to verify the information and to alleviate perceived risk which supports the findings of Xingyuan et al. (2010).

It is good to include prices, but they need to be precise and understandable. To present 'prices from' is perceived as rather misleading. Visuals are generally regarded as helpful in creating a more trustworthy image. Seeing happy customers helps to communicate some of the main points and adds a more emotive message to accompany the facts and figures. Evidence of awards also has a positive impact as well as links to social media sites. However some advertisements were perceived as looking cheap which then influenced the participants' perception of the brand.

Generally, the best liked and more trustworthy advertisements (see Tables 1-6) shared some common characteristics. The layout of advertisements appears important as both Italian and UK participants preferred advertisements with a simple and clear execution. The unanimous winner for both samples in our study was the advertisement for Lloyds (financial services) which was perceived to be well-balanced, clean, simple and fresh. Interestingly, this advertisement features a fictitious character which has previously been shown to increase trustworthiness (Garretson \& Niedrich, 2004). A number of the Italian participants also noted that they liked the green colour in the advertisement. Indeed, colour features more strongly in the responses by Italian participants generally. Cross-cultural research has found that a number of cultures associate blue (USA, Japan, Korea and China) and green (China) with trustworthiness as featured in a number of the more trustworthy advertisements, namely Tesco and 3, Halifax and Lloyds, and Global Enduro. Red is also associated with trustworthiness in China and represents the corporate colour of Virgin whose advertisement was found to be trustworthy by both UK and Italian participants. Aslam (2006, citing Crozier, 1996; Hupka., Zalenski, Otto, Riedl, \& Tarabrina, 1997) also highlights the importance of colour tone or hue in perception and association with behaviour. A "balanced" colour appears to be preferable as the blue colour in the Halifax (financial service) advertisement was thought to be too dark and therefore less trustworthy. Similarly, the light or translucent colours in the Kesari (travel) advertisement were perceived as too cold.

One finding that became clear during the focus groups was the strong link between previous brand knowledge and perception of the advertisements. As illustrated in the work of Xingyuan et al., (2010), user experience has a significant impact on how the brand is perceived. Our study shows that it also has a strong impact on perceptions of brand communications, even if the brand in question is being promoted in a product category where personal experience has not taken place e.g. Tesco and Virgin. Such brand trustworthiness is obviously invaluable and contributes greatly to brand equity. It is why brands like Tesco and Virgin can successfully extend their portfolio into new product categories such as financial services. This sector, as we said before, can be perceived as a "sensitive" field, where trust, created also thanks to advertisements, decreases the uncertainty in a background in which consumers feel especially exposed (Doney \& Cannon, 1997).

It is interesting to note the long list of "trustworthy brands" that were provided by the participants for each product category investigated. Again, the main reason given for each choice was user experience. This came through particularly strongly with financial services where a number of people talked about the brand being used by the family and the reference to "my bank". This seems to be in line with the idea of the prosumer, presented before. Indeed, the fact that many consumers identify themselves with 
a brand or consider a specific service or product to belong to "them " highlights that they really think to be involved both in production and in consumption rather than focusing on either one (production) or the other (consumption) (Ritzer \& Jurgenson, 2010).

On the other hand, this would suggest that it takes time to build a trustworthy identity too. Lopamudra and Subhadip (2011) suggest that perceived credibility is a result of the company being perceived as consistently competent and honest. The length of the lists indicates that the positioning of "trustworthy" does not seem to be occupied by any particular brand in these product categories at the present time which may present an opportunity to build brand credibility.

Tables 7 and 8 provide a list of the most trustworthy brands from our two country samples. It is worth noting that they cover a wide range of different products and services as well as examples of high and low involvement purchases. This is despite evidence to suggest that trustworthiness is more important

Table 7. List of most trusted brands (UK results)

\begin{tabular}{|c|c|c|}
\hline Phase Eight & Chanel & Apple \\
\hline Nivea & Papermate & M \& S \\
\hline John Lewis & $\underline{\text { VW }}$ & Virgin \\
\hline Selfridges & $\underline{\text { Adidas }}$ & Barlland and Barrett \\
\hline Nike & Heinz & Co-op \\
\hline T-Mobile & McDonald's & Amazon \\
\hline Tesco & ASOS & \\
\hline
\end{tabular}

Grey colour indicates similarities between UK and Italy in terms of most trusted brands.

Table 8. List of most trusted brands (Italy results)

\begin{tabular}{|c|c|c|}
\hline Adidas & Fix Design & Oviesse \\
\hline Alcott & Heineken & Poste Italiane \\
\hline Armani & Hogan (shoes) & Samsung \\
\hline Apple & Honda & Sisa (supermarket) \\
\hline Banco de Napoli & HP & Valsoia \\
\hline BMW & IKEA & VW \\
\hline Breil watch & Kimbo (coffee) & \\
\hline Carrefour & Lacoste & \\
\hline Ceres & Lavazza & \\
\hline Coca Cola & Malboro & \\
\hline D\&G & Microsoft & \\
\hline Diesel & Mulino Bianco & \\
\hline Dior & Nero Giardini & \\
\hline Ferrero & Nivea & \\
\hline Findus & Nutella & \\
\hline
\end{tabular}

Grey colour indicates similarities between UK and Italy in terms of most trusted brands. 
for high involvement product categories (Lantieri \& Chiagouris, 2009). However, the reasons provided for trusting a brand were less varied. Consistent quality came through very strongly, based on reputation and personal experience in line with some of the corporate image associations identified earlier. The size of the company, how long they have been established and their level of customer service were also highlighted by both UK and Italian participants and both samples agreed that Adidas, Apple, Nivea and VW represent such trustworthy brands. These are obviously all characteristics that can be communicated through advertising and will be explored in further research.

Lastly the participants were asked whether they trusted advertising. Their perception of advertising was influenced by the type of product being advertised and the advertisement itself. As participants in both countries put it "I only trust ads for trustworthy brands". If a customer has a positive opinion of a brand then that influences their perception of that brand's advertising. Brands that advertise a lot (usually leading brands) are generally perceived as more trustworthy as demonstrated by the suggested brand names above. It is conceivable that trustworthiness can be a processing filter in the same way as liking. Gordon (2006) contends that, if a brand is liked, we become more tolerant of its advertising. A number of participants used make-up and financial services as examples of products whose advertisements would be the least trustworthy. The fact that models were retouched and false eyelashes were used to promote mascara was cited as examples of how advertising tries to fool people. Indeed, an undercurrent prevailed in the responses which suggested a lack of trust and a feeling of being fooled e.g. "they rarely tell you the entire truth" and "don't trust most of them - strings attached". These findings support other evidence indicating that trust in brands is decreasing at a macro level (Lantieri \& Chiagouris, 2009). Customers are becoming more cynical about brands and their claims of being the best. They see that the emphasis on short term goals within organisations has led to quality inconsistencies, product recalls, and poor service encounters resulting in not wishing to have a "relationship" with all the brands that they buy.

\section{SOLUTIONS AND RECOMMENDATIONS}

Our findings show that students may combine a strong preference for a global brand with an equally strong preference for home-country products. Relevant differences are found between the two countries with respect to preferences for global and local brands. Actually, some participants especially in Italy, stated that they trust advertisements if they are linked with Italian brands. This could be seen as a typical effect of the "country-of-origin" and cultural barriers going up as mentioned earlier. For this reason, consistent with current trends of globalisation, each transnational company must be strongly interested in examining what affects the perception and evaluation of both global and local brands in different Countries (Schuiling \& Kapferer, 2004; Holt, Quelch, \& Taylor, 2004). In the current debate, an engaging area is that the appropriateness of purchasing decisions regarding foreign made products and the attitude towards home-country vs. global brands emerge as points of parity (Rosenbloom \& Haefner, 2009; Steenkamp \& de Jong, 2010).

This finding has relevant policy and managerial implications. Managers and communication agencies should pay attention to shaping and maintaining appropriate messages in order to maximize not only the selling and purchasing opportunities, but also the positive attitude in their potential and actual final customers that can lead to trust creation. Moreover, firms that are not yet oriented to pay attention to the highlighted items should learn how to grasp these information benefits from their extant competitors, in 
order to match their efforts with the opportunities of fulfilling consumers' needs. At the same time, the study focussed on the importance of emotive messages, visuals, and social media and these aspects could be further enhanced through some more formal innovation policy such as developing internal/external research and development project or sharing it with other firms and external institutions (universities and research centres).

Moreover, firms that sell and advertise their products/services abroad should try to develop a better understanding of final customers located in different countries in order to develop a deeper marketing effort in consumer behaviour scanning. Understanding foreign markets and the capacity to market products and services effectively abroad are vital factors for firms and constitute their core capabilities.

\section{FUTURE RESEARCH DIRECTIONS}

The limitations of the exploratory nature of our study, using a small sample with a focus on high involvement services and a set of heterogenic types of advertisements need to be addressed in future research. Our research hypotheses therefore represent a preliminary stage in this area of study, and it is important to present a research agenda to deepen studies of the following topics: ingredients of a trustworthy brand image; ingredients of a trustworthy advertisement; a comparison of these specific indicators in different contexts. Based on these considerations, future research should suitably be focused on several aspects:

First, studies should progressively reflect on how brand trustworthiness can influence advertisement trust. Research should investigate whether the approach to communicate varies between industries/ categories of products, and if the approach to communication depends upon the environmental context.

Second, further longitudinal research is still necessary. This research could follow the brand lifecycle and recognize the significant factors required for successful communication at different stages.

Third, although efforts have been made in this chapter to synthesise the main aspects of trust formation processes, there is a need for further research to develop a conceptual framework. Such analysis could provide a wider understanding of the processes by which trust is attained and developed also based on advertisements.

In addition, research may be undertaken to broaden this study - in an effort to assess the extent to which its findings may be generalised - or to test the hypotheses generated.

Future research is needed to provide more evidence as to whether advertising and brand trustworthiness is a multi-dimensional or one-dimensional construct. Perhaps the dimensions in this study could be redefined. A check could be made to see if the trust construct found here is applicable to a more geographically dispersed group of consumers. In addition, research is needed to further investigate potential product familiarity effects on product-culture matches and predictions of purchase intent. If respondents with little product familiarity evaluate matches differently, marketers will need to adapt their strategies accordingly.

The findings gathered from the student sample framework presented here should also be examined for other consumer groups. While comparable cross-national graduate student samples were used here, research on other socioeconomic groups should be conducted as well. Notwithstanding this suggestion a further sample of different informants is planned for the very near future. This will provide the researchers with another sample and enable a triangulation to be made. 
Cultural Perspectives on Advertising Perceptions and Brand Trustworthiness

\section{CONCLUSION}

The literature indicates that many brand image associations impact brand equity and ultimately purchase decisions and that brand trustworthiness is an important dimension of this process. We have focused on two main ideas in this chapter, namely how a trustworthy brand image in advertising can be created and brand preference towards local and global brands in a cross-cultural context.

A number of ideas have been advanced in this chapter about creating a trustworthy brand image in advertisements and also what constitutes responsible communication in achieving such trusted status for brands that are purchased in different countries. Our exploratory study examined advertisements for high involvement services and identified the ingredients needed to portray a trustworthy brand image. A more general objective was to explore why people trust certain brands and to identify any differences in perceptions of brand trustworthiness between UK and Italian consumers. The impact of user experience on brand trustworthiness comes through very strongly and brand owners need to ensure that their brands are consistently meeting consumers' expectations to encourage loyalty and positive WOM. However, the results from this initial research do indicate that advertising can assist in creating and maintaining a trustworthy image. It would seem that consumers generally value advertising that is clear, simple and straightforward. The use of colour and colour tone appears to be important in communicating trustworthiness when considering cross-cultural advertising and thus marketing managers must be mindful of what image they want their brand to portray in different cultures as our Italian consumers appear to have an acute perception of colour cues that influences attitude to the brand. We find that consumers are generally wary of being tricked in some way and quite cynical when it comes to deals, offers and small print. Tools that advertising practitioners can utilise to address this seems to be more emotive messages, possibly through visuals, evidence of awards, links to social media sites and indications of the size of organisation and how long they have been in operation. More research is necessary to explore these findings further as they are based on high involvement services and on a specific group of people, both limitations preventing generalisations to be made. Meanwhile perhaps advertisers should be more critical of their own efforts in attempting to build relationships with consumers, particularly younger segments, based on some of the poor practices that have been identified in this study indicating that more responsible communication would be valued by consumers. It is a sobering thought that young people are so critical of the advertising they are exposed to even for brands that they buy. Advertisers will need to take account of such a powerful voice in the marketplace whilst also adhering to domestic and international advertising regulations and laws to promote brand messages that have credibility.

We also found some relevant differences between the two countries with respect to preferences to global and local brands suggesting that Italians are more attached to local brands compared to their UK counterparts. Based on our findings, future research should focus on exploring the consumer preference for brands taking into consideration the importance they give to them. Thus product involvement should be measured as part of future studies as it plays a key role in advertising processing by directing attention and effort to evaluate advertisements that are interesting and relevant and filtering out those that are not (McQuarrie \& Munson, 1992; Petty \& Cacioppo, 1986). Moreover, while comparable cross-national graduate student samples were used here research on other socioeconomic groups should be conducted as well in order to examine the role that brand and advertising trustworthiness plays in advertising for different target audiences. 
Cultural Perspectives on Advertising Perceptions and Brand Trustworthiness

In brief, the chapter identifies that consumer attitudes towards brands still remain a contentious concept that deserves further research. This study thus lays a foundation for further development of both theory and practice in the area.

From a practical standpoint, the paper suggests to brand managers and policy decision-makers the criteria open to them to maximise 'trusting' brand features in their international marketing activities. On the theoretical point of view, branding came to be focussed on improving the expressiveness of company and establishing long-term relationship with all its customers.

\section{REFERENCES}

Ambler, T. (1997). How much brand equity is explained by trust? Management Decision, 35(4), 283-292. doi:10.1108/00251749710169666

Ashill, N. J., \& Sinha, A. (2004). An exploratory study into the impact of components of brand equity and country of origin effects on purchase intention. Journal of Asia-Pacific Business, 5(3), 27-43. doi:10.1300/J098v05n03_03

Aslam, M. M. (2006). Are you selling the right colour? A cross-cultural review of colour as a marketing cue. Journal of Marketing Communications, 12(1), 15-30. doi:10.1080/13527260500247827

Bennett, R., Härtel, C. E., \& McColl-Kennedy, J. R. (2005). Experience as a moderator of involvement and satisfaction on brand loyalty in a business-to-business setting, 02-314R. Industrial Marketing Management, 34(1), 97-107. doi:10.1016/j.indmarman.2004.08.003

Bradley, F. (1991). International marketing strategy. London: Prentice-Hall International.

Chaudhuri, A., \& Holbrook, M. B. (2001). The chain of effects from brand trust and brand affect to brand performance: The role of brand loyalty. Journal of Marketing, 65(2), 81-93. doi:10.1509/ jmkg.65.2.81.18255

Chen, S. C., \& Dhillon, G. S. (2003). Interpreting dimensions of consumer trust in e-commerce. Information Technology Management, 4(2/3), 203-318. doi:10.1023/A:1022962631249

Clark, H. (1987). Consumer and corporate values: Yet another view on global marketing. International Journal of Advertising, 6(1), 29-42.

Cui, Y., Trent, E. S., Sullivan, P. M., \& Matiru, G. N. (2003). Cause-related marketing: How generation Y responds. International Journal of Retail \& Distribution Management, 31(6), 310-320. doi:10.1108/09590550310476012

Delgado-Ballester, E. (2004). Applicability of a brand trust scale across product categories: A multigroup invariance analysis. European Journal of Marketing, 38(5/6), 573-592. doi:10.1108/03090560410529222

Delgado-Ballester, E., \& Munuera-Aleman, J. L. (2005). Does brand trust matter to brand equity. Journal of Product and Brand Management, 14(2/3), 187-196. doi:10.1108/10610420510601058

Doney, P. M., \& Cannon, J. P. (1997). An examination of the nature of trust in buyer-seller relationships. Journal of Marketing, 61(2), 35-51. doi:10.2307/1251829 
East, R. (1996). Consumer behavior: Advances and applications in marketing. London: Prentice Hall.

Garretson, J. A., \& Niedrich, R. W. (2004). Spokes-characters: Creating character trust and positive brand attitudes. Journal of Advertising, 33(2), 25-36. doi:10.1080/00913367.2004.10639159

Gordon, W. (2006). What do consumers do emotionally with advertising? Journal of Advertising Research, 46(1), 2-10. doi:10.2501/S0021849906060028

Gounaris, S., \& Vlasis, S. (2004). Antecedents and consequences of brand loyalty: An empirical study. Journal of Brand Management, 11(4), 283-206. doi:10.1057/palgrave.bm.2540174

Grimes, A., \& Doole, I. (1998). Exploring the relationship between colour and international branding - A cross cultural comparison between the UK and Taiwan. Journal of Marketing Management, 14(7), 799-817. doi:10.1362/026725798784867581

Gürhan-Canli, Z., \& Batra, R. (2004). When corporate image affects product evaluations: The moderating role of perceived risk. JMR, Journal of Marketing Research, 41(2), 197-205. doi:10.1509/ jmkr.41.2.197.28667

Holt, D.B., Quelch, J.A., \& Taylor, E.L. (2004, September-October). How global brands compete. Harvard Business Review, 68-75.

Hupka, R. B., Zalenski, Z., Otto, J., Riedl, L., \& Tarabrina, N. V. (1997). The colour of anger, envy, fear and jealousy: A cross-cultural study. Journal of Cross-Cultural Psychology, 28(2), 156-171. doi:10.1177/0022022197282002

Hyllegard, K., Yan, R., Ogle, J., \& Attmann, J. (2011). The influence of gender, social cause, charitable support, and message appeal on Gen Y's responses to cause-related marketing. Journal of Marketing Management, 27(1/2), 100-123.

Javidan, M., \& House, R. J. (2001). Cultural acumen for the global manager: Lessons from project GLOBE. Organizational Dynamics, 29(4), 289-305. doi:10.1016/S0090-2616(01)00034-1

Johnson, D., \& Grayson, K. (2005). Cognitive and affective trust in service relationships. Journal of Business Research, 58(4), 500-507. doi:10.1016/S0148-2963(03)00140-1

Kay, M. J. (2006). Strong brands and corporate brands. European Journal of Marketing, 40(7), 742-760.

Keillor, B. D., \& Hult, G. T. M. (1999). A five-country study of national identity. Implications for international marketing research and practice. International Marketing Review, 16(1), 68. doi:10.1108/02651339910257656

Keller, K. L. (1993). Conceptualising, measuring and managing customer-based brand equity. Journal of Marketing, 57(January), 1-22. doi:10.2307/1252054

Lafferty, B. A., Goldsmith, R. E., \& Newell, S. J. (2002). The dual credibility model: The influence of corporate and endorser credibility on attitudes and purchase intentions. Journal of Marketing Theory and Practice, 10(3), 1-12.

Lantieri, T., \& Chiagouris, L. (2007). Brand trust in an age without trust: Expert opinions. Journal of Consumer Marketing, 26(2), 78-86. doi:10.1108/07363760910940447 
Lantz, G., \& Loeb, S. (1996). Country of origin and ethnocentrism: An analysis of Canadian and American preferences using social identity theory. Advances in Consumer Research. Association for Consumer Research (U. S.), 23(1), 374-378.

Li, F., \& Miniard, W. (2006). On the potential for advertising to facilitate trust in the advertised brand. Journal of Advertising, 35(4), 101-112. doi:10.2753/JOA0091-3367350407

Littler, D., \& Schlieper, K. (1995). The development of the Eurobrand. International Marketing Review, 12(2), 22-37. doi:10.1108/02651339510089774

Lopamudra, G., \& Subhadip, R. (2011). Importance of 'trust factor' in corporate branding. The Journal of Business Strategy, VIII(4), 55-62.

Macdonald, E. K., \& Sharp, B. M. (2000). Brand awareness effects on consumer decision making for a common, repeat purchase product: A replication. Journal of Business Research, 48(1), 5-15. doi:10.1016/ S0148-2963(98)00070-8

McQuarrie, E. F., \& Munson, M. J. (1992). A revised product involvement inventory: Improved usability and validity. Advances in Consumer Research. Association for Consumer Research (U. S.), 19(1), 108-115.

Mead, G. (1993). A universal message. Financial Times, 27(May), 20.

Moorman, M., Zaltman, G., \& Deshpande, R. (1992). Relationships between providers and users of marketing research: The dynamics of trust within and between organizations. JMR, Journal of Marketing Research, 29(August), 314-329. doi:10.2307/3172742

Morgan, R. M., \& Hunt, S. D. (1994). The commitment-trust theory of relationship marketing. Journal of Marketing, 58(3), 20-38. doi:10.2307/1252308

Pappu, R., Quester, P. G., \& Cooksey, R. W. (2006). Consumer-based brand equity and country-oforigin relationships: Some empirical evidence. European Journal of Marketing, 40(5/6), 696-717. doi:10.1108/03090560610657903

Petty, R. E., \& Cacioppo, J. T. (1986). The elaboration likelihood model of persuasion. Advances in Experimental Social Psychology, 19, 123-205. doi:10.1016/S0065-2601(08)60214-2

Reast, J. D. (2005). Brand trust and brand extension acceptance: The relationship. Journal of Product and Brand Management, 14(1), 4-13. doi:10.1108/10610420510583707

Richardson, P. S., Dick, A. S., \& Jain, A. K. (1994). Extrinsic and intrinsic cue effects on perceptions of store brand quality. Journal of Marketing, 58(4), 28-36. doi:10.2307/1251914

Ritzer, G., \& Jurgenson, N. (2010). Production, consumption, prosumption: The nature of capitalism in the age of the digital "prosumer". Journal of Consumer Culture, 10(1), 13-16. doi:10.1177/1469540509354673

Rosenbloom, A., \& Haefner, J. E. (2009). Country-of-origin effects and global brand trust: A first look. Journal of Global Marketing, 22(4), 267-278. doi:10.1080/08911760903022432

Schmitt, B. H., \& Pan, Y. (1994). Managing corporate and brand identities in the Asia-Pacific region. California Management Review, 36(4), 32-48. doi:10.2307/41165765 
Schuiling, I., \& Kapferer, J.-N. (2004). Real differences between local and international brands: Strategic implications for international marketers. Journal of International Marketing, 12(4), 97-112. doi:10.1509/ jimk.12.4.97.53217

Sharma, S., Shimp, T. A., \& Shin, J. (1995). Consumer ethnocentrism: A test of antecedents and moderators. Journal of the Academy of Marketing Science, 23(1), 26-37. doi:10.1007/BF02894609

Shimp, T., \& Sharma, S. (1987). Consumer ethnocentrism: Construction and validation of the CETSCALE. JMR, Journal of Marketing Research, 24(3), 280-289. doi:10.2307/3151638

Siano, A., Vollero, A., \& Palazzo, M. (2011). Exploring the role of online consumer empowerment in reputation building: Research questions and hypotheses. Journal of Brand Management, 19(1), 57-71. doi:10.1057/bm.2011.23

Spry, A., Pappu, R., \& Cornwell, T. B. (2011). Celebrity endorsement, brand credibility and brand equity. European Journal of Marketing, 45(6), 882-909. doi:10.1108/03090561111119958

Steenkamp, J.-B. E. M., \& de Jong, M. G. (2010). A global investigation into the constellation of consumer attitudes towards global and local products. Journal of Marketing, 74(6), 18-40. doi:10.1509/ jmkg.74.6.18

Sumner, W. G. (1906). Folkways. Boston: Ginn.

Thakor, M. V., \& Kohli, C. S. (1996). Brand origin: Conceptualization and review. Journal of Consumer Marketing, 13(3), 27-42. doi:10.1108/07363769610147929

Toffler, A. (1980). The third wave (1st ed.). New York: Bantam Books.

Wang, A. (2010). The practices of mobile advertising disclosure on consumer trust and attitude. International Journal of Mobile Marketing, 5(2), 17-29.

Wang, J. (2005). Consumer nationalism and corporate reputation management in the global era. Corporate Communications: An International Journal, 10(3), 223-239. doi:10.1108/13563280510614483

Xingyuan, W., Li, F., \& Wei, Y. (2010). How do they really help? An empirical study of the role of different information sources in building brand trust. Journal of Global Marketing, 23(3), 243-252. doi:1 $0.1080 / 08911762.2010 .487425$

\section{ADDITIONAL READING}

Alden, D. L., Steenkamp, J., \& Batra, R. (2006). Consumer attitudes toward marketplace globalization: Structure, antecedents and consequences. International Journal of Research in Marketing, 23(3), 227-239. doi:10.1016/j.ijresmar.2006.01.010

Aref, A. A., Hayes, L. A., Zinkhan, G. M., \& Balazs, A. L. (2002). International Brand-Name Standardization/Adaptation: Antecedents and Consequences. Journal of International Marketing, 10(3), 22-48. doi:10.1509/jimk.10.3.22.19544 
Cultural Perspectives on Advertising Perceptions and Brand Trustworthiness

Arnett, J. J. (2002). The psychology of globalization. The American Psychologist, 57(10), 774-783. doi:10.1037/0003-066X.57.10.774 PMID:12369500

Askegaard, S., Arnould, E. J., \& Kjeldgaard, D. (2005). Postassimilationist ethnic consumer research: Qualifications and extensions. The Journal of Consumer Research, 32(1), 160-170. doi:10.1086/426625

Balabanis, G., Diamantopoulos, A., \& Melewar, T. C. (2001). The impact of nationalism, patriotism and internationalism on consumer ethnocentric tendencies. Journal of International Business Studies, 32(1), 157-177. doi:10.1057/palgrave.jibs.8490943

Balabanis, G., Mueller, R., \& Melewar, T. C. (2002). The human value's lenses of country of origin images. International Marketing Review, 19(6), 582-610. doi:10.1108/02651330210451935

Cleveland, M., Laroche, M., \& Papadopoulos, N. (2009). Cosmopolitanism, consumer ethnocentrism, and materialism: An eight-country study of antecedents and outcomes. Journal of International Marketing, 17(1), 116-146. doi:10.1509/jimk.17.1.116

Harzing, A. W., \& Sorge, A. M. (2003). The relative impact of country-of-origin and universal contingencies on internationalization strategies and corporate control in multinational enterprises: World-wide and European perspectives. Organization Studies, 24(2), 187-214. doi:10.1177/0170840603024002343

Holt, D. B. (2004). How brands become icons: The principles of cultural branding. Cambridge, MA: Harvard Business School Press.

Hung, C. (1989). A country of origin product image study: The Canadian perception and nationality biases. Journal of International Consumer Marketing, 13, 5-26. doi:10.1300/J046v01n03_02

Johansson, J. K., \& Nebenzahl, I. D. (1986). Multinational production: Effect on brand value. Journal of International Business Studies, 17(Fall), 101-126. doi:10.1057/palgrave.jibs.8490861

Kjeldgaard, D., \& Askegaard, S. (2006). The glocalization of youth culture: The global youth segment as structures of common difference. The Journal of Consumer Research, 33(2), 231-247. doi:10.1086/506304

Maheswaran, D. (1994). Country-of-origin as a stereotype: Effects of consumer expertise and attribute strength on product evaluations. The Journal of Consumer Research, 21(September), 354-365. doi:10.1086/209403

McCraken, G. (1986). Culture and consumption: A theoretical account of the structure and movement of the cultural meaning of consumer goods. The Journal of Consumer Research, 13(1), 71-84. doi:10.1086/209048

Ozsomer, A., \& Altaras, S. (2008). Global brand purchase likelihood: A critical synthesis and an integrated conceptual framework. Journal of International Marketing, 16(4), 1-28. doi:10.1509/jimk.16.4.1

Papadopoulos, N., \& Heslop, L. A. (Eds.). (1993). Product-country images: Impact and role in international marketing. Binghampton, NY: International Business Press.

Parameswaran, R., \& Yaprak, A. (1987). A cross-national comparison of consumer research measures. Journal of International Business Studies, 18(Spring), 35-49. doi:10.1057/palgrave.jibs.8490398 
Rajeev, B., Ramaswamy, V., Alden, D. L., Steenkamp, J. B. E. M., \& Ramachander, S. (2000). Effects of brand local and nonlocal origin on consumer attitudes in developing countries. Journal of Consumer Psychology, 9(2), 83-95. doi:10.1207/S15327663JCP0902_3

Roth, M. S., \& Romeo, G. B. (1992). Matching product category and country image perceptions: A framework for managing country of origin effects. Journal of International Business Studies, 13(Winter), 131-141.

Steenkamp, J.-B. E. M., Batra, R., \& Alden, D. L. (2003). How perceived globalness creates brand value. Journal of International Business Studies, 34(1), 53-65. doi:10.1057/palgrave.jibs.8400002

Strizhakova, Y., Coulter, R. A., \& Price, L. L. (2008). Branded products as a passport to global citizenship: Perspectives from developed and developing countries. Journal of International Marketing, 16(4), 57-85. doi:10.1509/jimk.16.4.57

Tomlinson, J. (1999). Globalization and culture. Chicago: University of Chicago Press.

Usunier, J. C. (1994). Social status and country of origin preferences. Journal of Marketing Management, 10(8), 765-782. doi:10.1080/0267257X.1994.9964320

Usunier, J. C. (2002). Le pays d'origine du bien influence-t-il encore les évaluations des consommateur? Revue Francaise du Marketing, 189/190, 49-65.

Yoo, B., Donthu, N., \& Lee, S. (2000). An examination of selected marketing mix elements and brand equity. Journal of the Academy of Marketing Science, 28(2), 195-211. doi:10.1177/0092070300282002

\section{KEY TERMS AND DEFINITIONS}

Attitudinal Loyalty: A person who feels positive towards a brand is "attitudinally" loyal. This is in contrast to someone who shops at the same place regularly and who is considered "behaviorally" loyal. Consumers can be both attitudinally loyal and behaviourally loyal at the same time or just one or the other.

Brand Equity: The value of a brand in the market place that is often measured in terms of loyalty to the brand.

Consumer Ethnocentricism: Ethnocentricism is the belief held by consumers about the appropriateness and morality of purchasing foreign-made products.

Cultural Homogeneity: Cultural homogeneity refers to different cultures that are very similar on certain dimensions e.g. uncertainty avoidance, gender differentiation, family collectivism etc.

Disclosure Information: Disclosure Information is terms and conditions of sale often referred to as the 'small print'.

Efficacy: Efficacy is the ability to produce a desired effect (in terms of how a brand is perceived in the market place through a variety of brand associations).

Experience Products: Experience products differ from search products as the quality and sometimes the price can be difficult to observe in advance. Search products are standard products where price and quality are known before consumption compared to a service/experience product where such characteristics are established upon consumption. 
Generation Y: Generation Y is generally referred to as individuals born between 1977 and 1994 representing a powerful segment of the global market due to its aggregate spending power.

Priming: Priming refers to the way stimuli (in advertising) is presented either visually or verbally. The idea is that priming of information affects how consumers process such cues.

Prosumers: Prosumers are a new type of consumer who is involved in the company's design as well as production process in order to help the company come up with products that could achieve mass acceptance, a process often referred to as 'co-creation'.

\section{ENDNOTE}

1 Although the views and ideas expressed in this chapter are those of Annie Danbury, Maria Palazzo, Kathleen Mortimer and Alfonso Siano; "Creating a Trustworthy Brand Image", "Impact of Culture on Brand Trustworthiness" and "Findings and Discussion" are attributed to Annie Danbury, "Issues of Consumer Etnocentricism", "Design, Approach and Methodology", "Solutions and Recommendations" and "Conclusion" to Maria Palazzo, "Abstract", "Introduction" and "Background" are attributed to Kathleen Mortimer, and "Future Research Directions" to Alfonso Siano.

This research was previously published in Analyzing the Cultural Diversity of Consumers in the Global Marketplace edited by Juan Miguel Alcántara-Pilar, Salvador del Barrio-García, Esmeralda Crespo-Almendros, and Lucia Porcu, pages 207-226, copyright year 2015 by Business Science Reference (an imprint of IGI Global). 